\title{
Short communication: Markers of oxidant status and inflammation relative to the development of claw lesions associated with lameness in early lactation cows
}

\author{
A. Abuelo, ${ }^{*}$ J. C. Gandy, $†$ L. Neuder, $†$ J. Brester, $†$ and L. M. Sordillo ${ }^{1}$ \\ *Graham Center for Agricultural Innovation, Charles Sturt University and NSW Department of Primary Industries, Wagga Wagga NSW 2678, \\ Australia \\ †Department of Large Animal Clinical Sciences, College of Veterinary Medicine, Michigan State University, East Lansing 48824
}

\section{ABSTRACT}

Lameness is a major health disorder of dairy cattle and evidence suggests that it may be associated with oxidative stress (OS) during the transition period. Some debate exists, however, as to whether OS precedes the development of lameness or if OS occurs as a consequence of lameness. The purpose of this study was to test whether cows showing claw lesions during early lactation had a greater pro-oxidant and inflammatory status throughout the dry period or at the start of the lactation. Blood samples were taken from 30 cows from the same herd at dry off, movement to the close-up pen, and between 3 and $7 \mathrm{~d}$ in milk. Sera were analyzed for concentrations of haptoglobin, serum amyloid A, reactive oxygen and nitrogen species, and antioxidant potential. Blood samples also were subjected to total and differential white blood cell counts. Animals were monitored through $120 \mathrm{~d}$ in milk and grouped ex post into the following health categories: (1) exclusively hoof lesions; (2) other production diseases; or (3) nondiseased. Changes in oxidant status and inflammatory markers were significantly different with respect to metabolic and physiologic adaptations to calving and lactation. No differences in oxidant status, acute phase protein concentrations, or leukocyte populations were observed between the hoof lesions and the nondiseased categories. Thus, any associations between OS and lameness likely occurs closer to the onset of clinical signs or as a consequence of inflammatory responses due to localized tissue injury.

Key words: dairy cow, inflammation, lameness, oxidative stress, transition period

Received December 2, 2015.

Accepted March 12, 2016.

${ }^{1}$ Corresponding author: sordillo@msu.edu

\section{Short Communication}

Lameness is a major health disorder of dairy cattle that not only causes substantial production-related losses, but also has animal welfare implications due to severe pain (Cha et al., 2010). Lameness is a multifactorial disease that can result from a variety of causative factors, including diet, housing conditions, concurrent diseases, and genetic influences. Evidence is growing, however, suggesting that lameness also might be triggered during the transition period (Proudfoot et al., 2010; Lim et al., 2015).

Dairy cattle undergo substantial metabolic and physiological adaptations as they shift from late pregnancy to early lactation (Bell, 1995). When the production of pro-oxidants exceeds the antioxidant capacity of exposed tissues during times of enhanced metabolism, this often leads to the progressive development of oxidative stress (OS) in transition cows (Bernabucci et al., 2005; Castillo et al., 2005). The role of OS as an underlying cause of disturbances in the inflammatory responses and increased susceptibility to transition cow disorders is well supported by the current literature (Lykkesfeldt and Svendsen, 2007; Sordillo and Aitken, 2009).

Previous studies reported that dairy cows with claw lesions (Al-Qudah and Ismail, 2012) or abnormal gait (Zhao et al., 2015) show a higher systemic pro-oxidant status than their healthy counterparts at the time of the diagnosis. Biomarkers of OS also were elevated in sheep with hoof lesions (Talukder et al., 2015); however, these studies have proven an association between OS and lameness, but causality remains unexplored. Information is also lacking whether changes in oxidant status are a risk factor associated with the development of lameness in early-lactation cows. Changes in redox status are known to activate several inflammatory pathways (Sordillo and Aitken, 2009; Shi et al., 2015). Thus, enhanced pro-oxidant status of transition cows could potentially increase proinflammatory mediators in the corium, leading to lameness. We hypothesized that cows developing claw horn disruption during early 
Table 1. Ingredients and chemical composition of the diets supplied to the animals at the different stages of the present study

\begin{tabular}{|c|c|c|c|c|c|}
\hline \multirow[b]{2}{*}{ Item } & \multicolumn{2}{|c|}{ Dry off } & \multicolumn{2}{|c|}{ Close up } & \multirow[b]{2}{*}{ Fresh } \\
\hline & Heifers & Cows & Heifers & Cows & \\
\hline Total DM offered, kg & 10.2 & 11.9 & 11.3 & 13.0 & 17.9 \\
\hline \multicolumn{6}{|l|}{ Nutrient analysis } \\
\hline DM, $\%$ & 45.7 & 42.37 & 51.9 & 48.15 & 50.4 \\
\hline $\mathrm{CP}, \%$ of $\mathrm{DM}$ & 14.6 & 14.3 & 16.0 & 14.9 & 17.7 \\
\hline MP, g & $1,005.8$ & $1,026.3$ & $1,185.8$ & $1,371.4$ & $2,354.3$ \\
\hline NDF, $\%$ of DM & 44.2 & 51.3 & 46.2 & 43.9 & 18.34 \\
\hline Starch, $\%$ of DM & 6.9 & 6.8 & 16.6 & 13.5 & 27.7 \\
\hline $\mathrm{Ca}, \%$ of DM & 0.69 & 0.75 & 0.95 & 1.59 & 0.78 \\
\hline $\mathrm{P}, \%$ of $\mathrm{DM}$ & 0.34 & 0.28 & 0.35 & 0.41 & 0.39 \\
\hline $\mathrm{Mg}, \%$ of $\mathrm{DM}$ & 0.44 & 0.39 & 0.41 & 0.50 & 0.31 \\
\hline $\mathrm{K}, \%$ of $\mathrm{DM}$ & 2.12 & 1.95 & 1.24 & 0.96 & 1.34 \\
\hline $\mathrm{Na}, \%$ of $\mathrm{DM}$ & 0.33 & 0.14 & 0.05 & 0.11 & 0.39 \\
\hline $\mathrm{Cl}, \%$ of $\mathrm{DM}$ & 0.28 & 0.28 & 0.20 & 0.47 & 0.53 \\
\hline S, $\%$ of $\mathrm{DM}$ & 0.14 & - & 0.24 & 0.45 & 0.24 \\
\hline $\mathrm{DCAD}, \mathrm{mEq} / \mathrm{kg}$ & 15.02 & 13.65 & 5.33 & 6.16 & 15.8 \\
\hline $\mathrm{Zn}, \mathrm{mg} / \mathrm{kg}$ & 37.7 & - & 82.2 & 106.2 & 75.7 \\
\hline $\mathrm{Cu}, \mathrm{mg} / \mathrm{kg}$ & 7.85 & - & 18.7 & 24.1 & 17.2 \\
\hline $\mathrm{Mn}, \mathrm{mg} / \mathrm{kg}$ & 26.26 & 0.39 & 61.3 & 79.1 & 56.4 \\
\hline $\mathrm{Se}, \mathrm{mg} / \mathrm{kg}$ & 0.71 & 0.61 & 0.57 & 0.70 & 0.32 \\
\hline $\mathrm{Co}, \mathrm{mg} / \mathrm{kg}$ & 0.43 & - & 1.05 & 1.35 & 0.9 \\
\hline $\mathrm{I}, \mathrm{mg} / \mathrm{kg}$ & 0.43 & - & 1.05 & 1.35 & 0.9 \\
\hline Vitamin A, kIU/kg & 15.56 & 9.22 & 15.56 & 17.22 & 9.52 \\
\hline Vitamin $\mathrm{D}, \mathrm{kIU} / \mathrm{kg}$ & 2.20 & 1.79 & 2.73 & 4.41 & 1.68 \\
\hline Vitamin $\mathrm{E}, \mathrm{kIU} / \mathrm{kg}$ & 192.0 & 162.3 & 167.1 & 158.7 & 39.68 \\
\hline ME, Mcal $/ \mathrm{kg}$ & 2.47 & 2.20 & 2.49 & 2.84 & 3.06 \\
\hline $\mathrm{NE}_{\mathrm{L}}, \mathrm{Mcal} / \mathrm{kg}$ of $\mathrm{DM}$ & 1.43 & 1.28 & 1.52 & 1.59 & 1.81 \\
\hline Monensin, mg/d & - & - & 273.1 & 336.0 & 379.9 \\
\hline
\end{tabular}

lactation had higher pro-oxidant status during the dry period and early lactation compared with healthy cows. Therefore, the aim of our study was to compare the expression of markers indicative of oxidant status and inflammation from the time of dry off to early lactation between cows that developed hoof lesions with those that remained healthy throughout the first several months of lactation.

The protocols used in our study were approved by the Michigan State University Institutional Animal Care and Use Committee and cows were enrolled with owner consent. This prospective study was conducted on a large commercial dairy farm associated with the Michigan State University Training Center for Dairy Professionals (Elsie, MI) from October 2014 to April 2015. This farm has an average of 3,300 lactating cows with a rolling herd average milk production of $12,250 \mathrm{~kg} /$ cow. Cows were housed in freestall barns, with cubicles bedded with sand, and grouped according to lactation number, DIM, and milk yield. Cows were milked 3 times daily in a double 40-stall or double 30-stall herringbone milking parlor. Feed alleys and walkways to and from the milking parlor had grooved concrete flooring. Alleys were cleaned with scrapers 3 times daily when cows were away for milking. Footbaths consisted of a $1 \%$ copper sulfate solution applied for 3 consecutive milk- ings, once a week for lactating, dry cows, and heifers, and twice a week in the cow and heifer close-up pens. All cows were fed a TMR (Table 1) delivered twice daily. Lactating cows were dried off approximately 60 $\mathrm{d}$ before the expected calving date. For this study, 30 pregnant Holstein cows (10 heifers, 10 cows entering their second lactation, and 10 cows entering their third or greater lactation) were randomly selected according to proximity in their expected calving date. Cows were followed from dry off until $120 \mathrm{~d}$ after calving.

On the farm, cow hooves were trimmed routinely at 120 to 150 DIM, at dry off (DO), and when showing signs of abnormal gait by the same trained foot-trimmer that also classified the lesions according to the modified ABC system of hoof lesion scoring (Burgi and Cook, 2006). Data on lesion location or severity also were recorded (data not shown). All claws of the animals enrolled in the study were examined by the foot trimmer at DO and 120 DIM. Only cows without claw lesions at enrolment (DO) were included in the study. Two members of the farm personnel, trained on mobility scoring, systematically monitored the cows weekly during the trial after TMR delivery and while the cows came out of the milking parlor. Lame cows were reported to the herd manager, who assessed the cow and presented it to the foot trimmer within a fortnight if the mobility 
score was $\geq 3$ on a 1 to 5 scale (Sprecher et al., 1997). All claws were subsequently examined and treated if necessary following the farm's protocols.

Fresh cows were checked daily by the farm personnel for the determination of rectal temperature, the presence of displaced abomasum and for the presence of acetoacetate (Ketostix, Bayer Corporation, Elkhart, IN) in urine. Displaced abomasa were confirmed by one of the herd veterinarians and sick cows were treated according to the farm's protocols.

Blood samples were taken from cows at the time of enrolment (DO; $57.9 \pm 1.75$ d before real calving date), when moved to the close-up pen $(\mathbf{C U} ; 14.3 \pm 1.42 \mathrm{~d}$ before real calving date), and $1 \mathrm{wk}$ after calving [between 3 and 7 DIM $(\mathbf{C + 7}) ; 6.61 \pm 0.31 \mathrm{~d}$ after calving]. Blood was drawn by coccygeal venipuncture into evacuated tubes with EDTA and without anticoagulants for serum collection. All samples were immediately placed on ice and transported to the laboratory. Serum tubes were subsequently centrifuged at $2,000 \times g$ for $18 \mathrm{~min}$ at $4^{\circ} \mathrm{C}$ and the supernatant serum harvested, aliquoted, snap-frozen in liquid nitrogen, and stored at $-80^{\circ} \mathrm{C}$ pending analysis within 2 mo of sample collection. The EDTA tubes were shipped overnight under refrigeration to Advanced Animal Diagnostics Inc. (Morrisville, $\mathrm{NC}$ ), for white blood cell differential counts, performed in duplicates by 2 independent clinical pathologists using Wright stain. The BCS of each cow was determined at each sample time using a 5-point scale with 0.25 intervals ( $1=$ lean, $5=$ obese; Edmonson et al., 1989).

Commercially available assays were employed to quantify the serum concentration of albumin (Albumin, Beckman Coulter Inc., Brea, CA), fatty acids [HR Series NEFA-HR(2), Wako Life Sciences, Mountain View, $\mathrm{CA}$, and BHB (Catachem Inc., Bridgeport, CT) by colorimetric measurement on an autoanalyzer (Olympus AU 640e, Beckman Coulter Inc.) at the Michigan State University Diagnostic Center for Population and Animal Health (East Lansing, MI), with appropriate controls for quality control. Reactive oxygen and nitrogen species (RONS) were quantified in serum as a marker of pro-oxidant production using a commercially available assay (ROS and RNS assay, Cell Biolabs, San Diego, CA) following the manufacturer's instructions. In brief, free radicals in the sample react with a specific probe that is converted into a highly fluorescent product. Thus, the fluorescent intensity is proportional to the total RONS content in the sample. Fluorescence of the dichlorofluorescent dye was determined at $480 \mathrm{~nm}$ of excitation and $530 \mathrm{~nm}$ of emission and a standard dichlorofluorescent dye curve was included to ensure that the dye could be detected at various concentrations. Blank values were subtracted from sample values to eliminate background fluorescence. The reported val- ues represent relative fluorescent units normalized per microliter of sample. The antioxidant potential (AOP) was measured in serum using the trolox equivalents antioxidant capacity as previously described (Re et al., 1999). Briefly, the AOP of a sample was expressed as the equivalence of a known trolox (synthetic vitamin E analog) standard (Sigma-Aldrich, St. Louis, MO) concentration resulting in a similar reduction of the generated radical 2,2'-azino-bis-3-ethylbenzothiazoline6 -sulfonic acid (Sigma-Aldrich) determined using the standard curve. Because of the difficulty in measuring each antioxidant component separately and the interactions among different antioxidants components in the serum, this test accounts for all the antioxidants present in the sample (albumin, bilirubin, uric acid, thiol groups, vitamins, glutathione, glutathione peroxidase, superoxide dismutase, catalase, and so on). Both parameters of the redox balance were assessed together as the ratio of pro-oxidant to total antioxidant defenses (RONS/AOP), namely oxidative stress index (OSi), as it accurately detects changes in oxidant status during the transition (Abuelo et al., 2013). An increase in the ratio indicates a higher risk for OS due to an increase in pro-oxidant production or defensive antioxidant consumption.

Haptoglobin (Hp) and serum amyloid A (SAA) were determined as positive acute phase proteins. A commercial photometric colorimetric kit was employed for assessing Hp (Phase Haptoglobin Assay; Tridelta Development Ltd., Maynooth, Ireland), with intra- and interassay coefficients of variation of 5.9 and $6.3 \%$, respectively. The SAA concentration was determined using a commercial ELISA kit (Phase SAA Assay; Tridelta Development Ltd.), for which the intra- and interassay coefficients of variation were 5.4 and $9.8 \%$, respectively. The detection limits were $2.5 \mathrm{mg} / \mathrm{mL}$ and $0.3 \mu \mathrm{g} / \mathrm{mL}$ for $\mathrm{Hp}$ and SAA, respectively.

Clinical mastitis was diagnosed by the farm personnel when a cow showed abnormalities in the udder or the milk, such as watery appearance, clots, and flakes. Subclinical mastitis was defined when a cow had a SCC $>250,000$ cells $/ \mathrm{mL}$ during the study period. Retained placenta was defined as a failure to expel fetal membranes within $24 \mathrm{~h}$ after calving. Metritis was defined as the presence of fetid, watery, red-brown uterine discharge. Hyperketonemia was defined as either serum BHB concentration $\geq 1.2 \mathrm{mmol} / \mathrm{L}$ (McArt et al., 2013) in the $\mathrm{C}+7$ sample or a positive acetoacetate urine strip $(>15 \mathrm{mg} / \mathrm{dL})$ during the first month in milk. Thresholds of 0.29 and $0.57 \mathrm{mEq} / \mathrm{L}$ of fatty acids (Ospina et al., 2010) were used to determine excessive lipid mobilization in pre- and postpartum serum samples, respectively. A displacement of the abomasum was defined by the presence of a ping sound by simultaneous 
auscultation-percussion and auscultation-ballottement in one of the cow's flanks.

Dairy cows were grouped ex post at the end of the study considering their health status. Cows that were exclusively diagnosed with claw horn lesions were assigned to the hoof lesions category $(\mathbf{H L})$. Cows that developed other clinical or subclinical postpartum diseases (retained placenta, metritis, mastitis, displaced abomasum, excessive lipid mobilization, or hyperketonemia) only or concurrently with lameness were allocated to the other production diseases category (OPD). Cows that did not develop any of these diseases during the study period and showed no claw lesions at the examination at 120 DIM were assigned to the nondiseased category (ND). Three cows were culled before the completion of the study because of dystocia (1) and undifferentiated diarrhea with high temperature (2) at 2, 26, and 31 DIM, respectively; their data were excluded. The final animal numbers for each health category consisted of HL $(\mathrm{n}=7)$, OPD (n $=12)$, and ND ( $\mathrm{n}=8)$. According to the final distribution of cows into health categories, the study has a power of $74.5 \%$ to detect changes between the HL and ND groups with a standard deviation of 3.0 and an $\alpha=$ 0.05 . Within each category, parity distribution was as follows: 2 heifers, 3 cows entering the second lactation, and 3 cows entering third or greater lactation in the HL group; 2, 6, and 4, respectively, in the OPD group; and 4,1 , and 2 in the ND group.

Mixed models were built on JMP Pro v11 (SAS Institute Inc., Cary, NC) for the dependent variables RONS, AOP, OSi, Hp, SAA, albumin, fatty acids, BHB, and BCS. The fixed effects included were health category (HL, OPD, ND) and parity $(1,2, \geq 3)$, with the repeated statement for the time variable ( $\mathrm{DO}, \mathrm{CU}, \mathrm{C}+7)$; cow identification was the random effect. All 2-way interactions were offered to the model. Interaction terms were removed from the model unless they had a significant effect $(P \leq 0.05)$; the interaction of health category and time was forced into every model.

To account appropriately for within-cow correlation, the error term was modeled by imposing a first-order autoregressive covariance structure for all statistical models. Tukey's post hoc test was used for comparison of means among all groups when the results of the ANOVA analysis yielded a $P$-value of $\leq 0.05$. Normality of residuals was tested after each model fit by visual evaluation of the distribution of the residuals in $\mathrm{Q}-\mathrm{Q}$ plots. When the residuals were not normally distributed, the data were logarithmically transformed and the residuals distribution rechecked.

Cows enrolled in the HL group were diagnosed as lame at $58.6 \pm 5.02$ (mean \pm SEM) DIM. From the 7 HL cows, 6 were identified lame before the end of the trial and the remaining 1 had a lesion of claw horn disruption identified at the 120 DIM examination but was not visibly lame. Animals in the HL category showed only claw horn disruption lesions: 2 cows had exclusively sole ulcers, 3 cows only white line disease (2 fissures and 1 abscess), and 2 cows had concurrently sole ulcers and white line disease (1 fissure and 1 abscess); therefore, the lesions of the HL cows were restricted to the claws.

Disease diagnosis in the OPD group averaged at 13.6 \pm 2.74 DIM. From the 12 animals in the OPD group, 9 had ketosis, 6 had excessive lipid mobilization, 4 had mastitis, 3 had retained placenta, 2 had a displaced abomasum, and 1 had metritis. Three animals in the OPD group had also foot lesions (2 digital dermatitis, 1 sole ulcer) concurrent with other diseases. Eight of the 12 OPD cows had more than one condition.

Only time and parity had a significant effect on the concentration of RONS (Table 2). Production of free radicals was significantly lower at the DO stage and higher in primiparous cows (Table 3). On the other hand, the antioxidant potential was influenced by time and the time $\times$ category interaction. When these 2 variables were assessed together with the OSi, only the effects of time and parity significantly influenced its ratio. Several studies have reported variations in the expression of OS markers around the time of calving in multiparous cows (Bernabucci et al., 2005; Castillo et al., 2005; Abuelo et al., 2013), reflecting the changes in metabolic activity associated with the onset of lactation. This finding also was reported in heifers (Wullepit et al., 2009); although, to the best of our knowledge, the oxidant status of primiparous and multiparous cows was not previously compared. However, a lack of critical cut-off values exists for OS biomarkers in cattle (Sordillo and Mavangira, 2014; Abuelo et al., 2015). Hence, it cannot be inferred whether the higher degree of pro-oxidant production showed by heifers affects animal performance or is just associated with the different physiological processes that heifers and multiparous cows go through.

The AOP decreased from $\mathrm{CU}$ to $\mathrm{C}+7$. This decrease can be associated with effectively counteracting the pro-oxidant challenge associated with increased metabolism during the onset of lactation, the decrease in the amount of vitamins provided in the fresh ration, the use of antioxidants in colostrum synthesis (Goff and Horst, 1997), or the decreased hepatic production of different vitamin carrier proteins in the peripartum (Abd Eldaim et al., 2010). Also, we were not able to find differences in RONS among health categories; however, several studies have reported a marked individual variation in terms of pro-oxidants production for several biomarkers in periparturient cattle (Castillo et al., 2005, 2006; 
ABUELO ET AL.

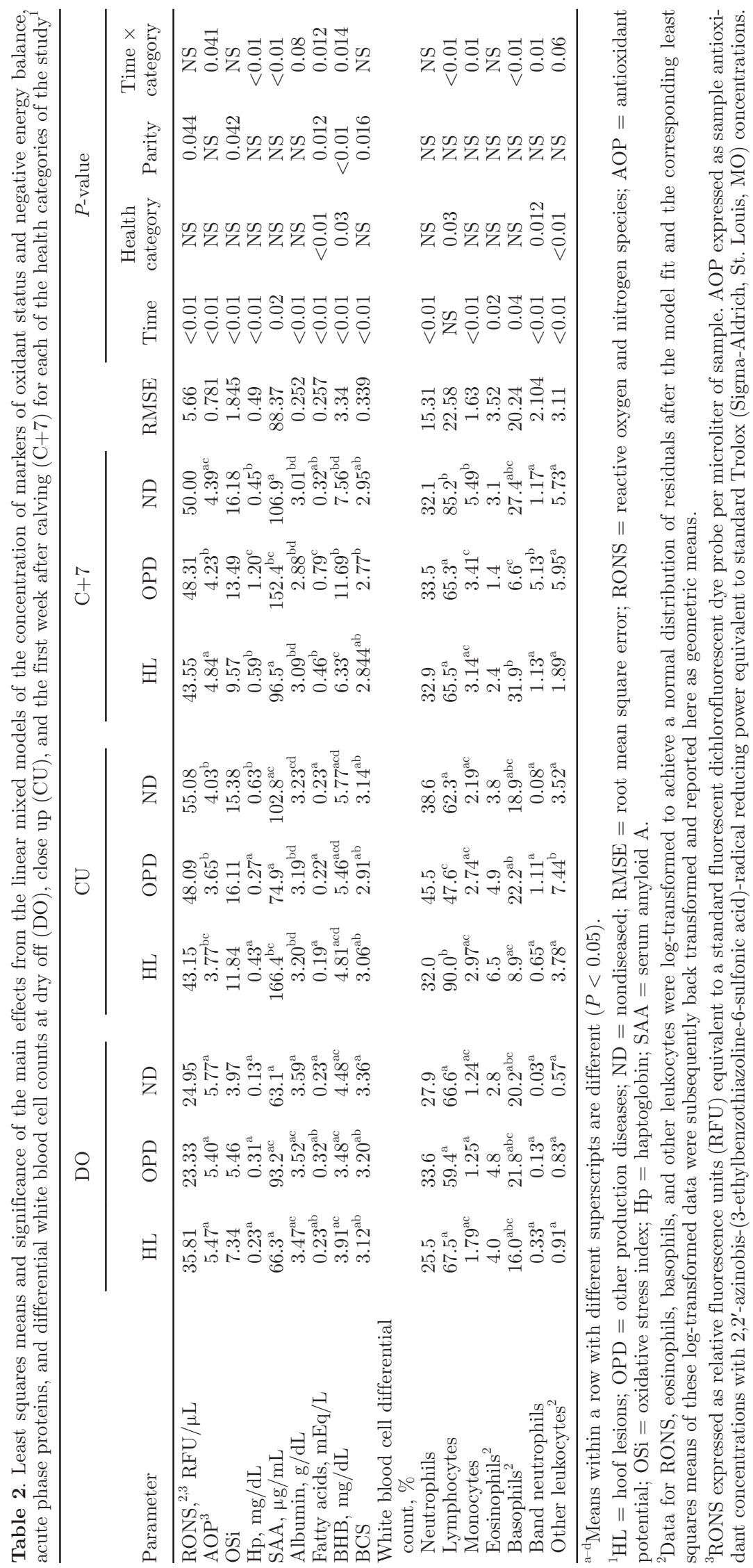


SHORT COMMUNICATION: LAMENESS AND OXIDANT STATUS
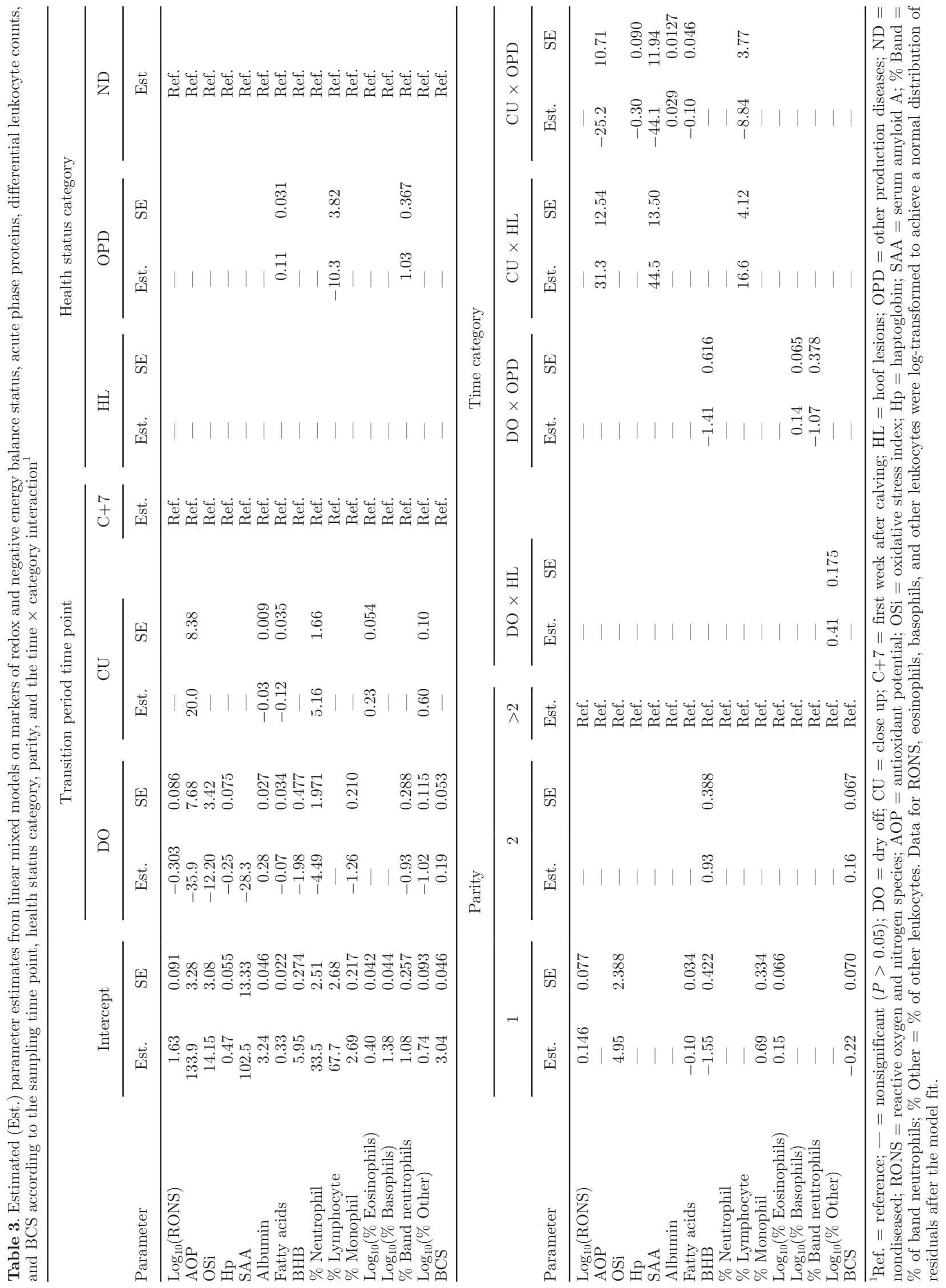
Abuelo et al., 2013), which was also found in our study. Hence, the individual cow variation in addition to the limited number of cows per group might explain the lack of differences in RONS production among health categories. However, these assays were used successfully by our research group to detect increased RONS production in blood and milk of cows suffering acute coliform mastitis with a similar sample size along with several other measures of oxidant status (Mavangira et al., 2016). Thus, the lack of significant change in the RONS production in the OPD group may be explained by the diversity of health disorders with distinctly different modes of pathogenesis that could influence redox status differently. Additionally, the lack of difference between groups can also be caused by the accuracy of the lameness identification method employed.

Previous studies reported increased pro-oxidant activity in cows with claw lesions or altered gait (Al-Qudah and Ismail, 2012; Zhao et al., 2015), although these studies measured different OS biomarkers than the ones employed in our study. In both previous studies, the authors used several individual antioxidants (superoxide dismutase, catalase, glutathione peroxidase, and so on) to account for changes in the antioxidant potential, and estimated damage due to OS through the direct quantification of malondialdehyde, a product of lipid peroxidation, or estimating this compound by quantifying the thiobarbituric acid reactive substances. However, it is difficult to account for the interaction in the sample of all the antioxidants if only a fraction are quantified independently; therefore, measures of total antioxidant potential consider the cumulative action of all antioxidants in the sample as an integrated variable (Ghiselli et al., 2000). Additionally, only a fraction of the quantified malondialdehyde is actually generated in vivo, and thiobarbituric acid reactive substances lack specificity to this molecule because they can react with metabolites derived from other macromolecules (Halliwell and Chirico, 1993; Celi, 2011). Currently no information is available about the reference intervals for OS biomarkers or which assays may be more sensitive in detecting changes in redox status or OS in dairy cattle. The ability to establish standardized cut-off values for the most reliable indicators of redox change and OS will benefit the field immensely.

Previous studies examining the relationship between oxidant status and lameness determined that OS was present when the cows were already showing clinical signs, so it is not certain whether OS was a cause or a consequence of lameness. Oxidative stress is an underlying factor for dysregulated inflammatory responses (Sordillo and Aitken, 2009), and some research has shown that lameness might be triggered during the dry period and start of lactation (Proudfoot et al., 2010; Lim et al., 2015). Thus, we hypothesized that those animals showing hoof lesions would show a higher prooxidant status than healthy animals during the dry period and the onset of lactation. However, contrary to our initial hypothesis, the health category did not show a significant effect on any of the oxidative status markers employed in our study. This suggests that either the development of OS in cases of lameness occurs closer to the onset of clinical signs or is just a consequence of the inflammation associated with the injured tissue. However, considering the relatively slow claw horn growth rate (Prentice, 1973), a considerable amount of time from injury to the stratum basalis of the corium epidermal tissues to claw horn disruption lesions is expectable and, therefore, the association of OS and lameness reported in other studies is more likely to be a consequence of the inflamed tissues. It is also worth noting that these previous studies are based on the assumption that systemic OS reflects accurately the local microenvironment in the corium tissue, whereas it has been shown that the local OS in some tissues is weakly correlated with systemic biomarkers of OS (Argüelles et al., 2004). Hence, in light of the outcomes of our study, this assumption remains unproven.

The concentrations of positive (Hp and SAA) and negative (albumin) acute phase proteins were affected only by time and time $\times$ category interaction. The period around parturition is associated with a high degree of inflammation (Bertoni et al., 2008), and the concentration of acute phase proteins usually raise before the observation of clinical signs of disease (Ceciliani et al., 2012), making these analytes of interest for early detection of animals at increased risk for suffering diseases or reduced milk yield or compromised reproductive performance (Huzzey et al., 2015). However, the health category did not have an effect on the concentration of acute phase proteins. Only the OPD showed at the $\mathrm{C}+7$ sampling point a significantly higher concentration than the HL and ND categories (Table 2), but this increase could be just explained by the inflammation of the affected tissues (i.e., mastitis, metritis, and so on) at the sampling time. Hence, we were not able to identify changes in the concentration of acute phase proteins during the dry period and the first week of lactation in cows that developed claw lesions at a later time. Conversely, a recent nested case-control study reported differences in $\mathrm{Hp}$ and SAA concentrations $4 \mathrm{wk}$ before calving between lame and nonlame cows (Zhang et al., 2015). However, those authors only included severely lame cows (mobility score $=5$ ) diagnosed at 1 to 3 wk after calving. As lameness is often a progressive disease (Bicalho and Oikonomou, 2013) the cows could 
be already mildly lame at $-4 \mathrm{wk}$, and therefore the differences reported could be attributed to the inflammation of the claw tissue at that time.

Fatty acids, BHB, and BCS showed significant changes with time and parity (Table 2). However, an increase in the degree of lipolysis and ketogenesis is expected around the time of calving, and until the concentration of fatty acids overwhelms the metabolic capacity of the liver, no association with diseases are found (Sordillo and Raphael, 2013). The concentrations of fatty acids and BHB were influenced by the health category, being higher in the OPD (Table 3). Although excessive lipid mobilization has been associated with several pathological conditions (McArt et al., 2013), in the current study we used the concentration of fatty acids and BHB above the established critical threshold as a classifying criterion for the OPD category; as a consequence, it is expected that the concentration of these variables are higher in this group. It is of note that the HL category did not show greater degree of lipolysis or ketogenesis than the ND category. Bicalho and Oikonomou (2013) suggested that mobilization of fat tissue from the digital cushion reduces its shock-absorbing capacity and predisposes to claw horn disruption lesions; however, in their studies they measured the digital cushion at the time of lameness diagnosis, thereby suggesting that the effect of fat mobilization on claw lesions might occur closer to the onset of clinical signs of lameness, rather than during the periparturient period.

Heifers showed lower lipid mobilization and production of ketone bodies than multiparous cows, also showing a significantly lower BCS (Table 3). This is a surprising finding considering that heifers showed greater RONS production than multiparous cows, as cows with higher BCS are expected to produce more free radicals during the transition period (Bernabucci et al., 2005; O'Boyle et al., 2006). Hence, the degree of metabolic stress in cows entering their first lactation and its association with diseases merits further research.

Some causes of lameness are associated with an excessive innate immune response (Refaai et al., 2013). Hence, we also investigated the changes in the populations of white blood cells during the study period. Apart from the percentage of lymphocytes, all the other leukocytes showed changes with time (Table 2). It is now well known that dairy cattle experience immunosuppression around the time of calving, starting several weeks before parturition (Goff and Horst, 1997), due to the demands of the mammary gland (Nonnecke et al., 2003). The health category only had an effect on the proportion of lymphocytes and band neutrophils (Table 2), but this effect was due to the OPD category (Table 3), in which animals with inflammatory or infectious conditions (i.e., mastitis, metritis, and so on) are included; and the lymphopenia and increased proportion of band neutrophils might just be due to the infection or inflammation associated with these conditions. Hence, no differences in the population of white blood cells during the dry period and onset of lactation were associated with the development of claw lesions later on.

The development of claw lesions during early lactation was not associated with prior indications of oxidant status, inflammatory response, or shifts in the white blood cells during the dry period or at the start of the lactation. Thus, previous reports in other studies of an association between OS and lameness may either take place closer to the onset of clinical signs of lameness or develop as a consequence of the inflammation of the injured tissue.

\section{ACKNOWLEDGMENTS}

This study was supported by the Agriculture and Food Research Initiative competitive grant no. 201468004-21972 from the USDA National Institute of Food and Agriculture (NIFA, Washington, DC) and an endowment from the Matilda R. Wilson Fund (Detroit, MI). The authors wish to thank Advanced Animal Diagnostics, Inc. (Morrisville, NC) for conducting the white blood cell differential counts.

\section{REFERENCES}

Abd Eldaim, M. A., A. Kamikawa, M. M. Soliman, M. M. Ahmed, Y. Okamatsu-Ogura, A. Terao, T. Miyamoto, and K. Kimura. 2010. Retinol binding protein 4 in dairy cows: Its presence in colostrum and alteration in plasma during fasting, inflammation, and the peripartum period. J. Dairy Res. 77:27-32. http://dx.doi. org/10.1017/S0022029909990276.

Abuelo, A., J. Hernandez, J. L. Benedito, and C. Castillo. 2013. Oxidative stress index (OSi) as a new tool to assess redox status in dairy cattle during the transition period. Animal 7:1374-1378. http://dx.doi.org/10.1017/S1751731113000396.

Abuelo, A., J. Hernandez, J. L. Benedito, and C. Castillo. 2015. The importance of the oxidative status of dairy cattle in the periparturient period: revisiting antioxidant supplementation. J. Anim. Physiol. Anim. Nutr. (Berl.) 99:1003-1016. http://dx.doi. org/10.1111/jpn.12273.

Al-Qudah, K. M., and Z. B. Ismail. 2012. The relationship between serum biotin and oxidant/antioxidant activities in bovine lameness. Res. Vet. Sci. 92:138-141. http://dx.doi.org/10.1016/j. rvsc.2010.10.017.

Argüelles, S., S. García, M. Maldonado, A. Machado, and A. Ayala. 2004. Do the serum oxidative stress biomarkers provide a reasonable index of the general oxidative stress status? Biochim. Biophys. Acta 1674:251-259. http://dx.doi.org/10.1016/j. bbagen.2004.06.023.

Bell, A. W. 1995. Regulation of organic nutrient metabolism during transition from late pregnancy to early lactation. J. Anim. Sci. 73:2804-2819.

Bernabucci, U., B. Ronchi, N. Lacetera, and A. Nardone. 2005. Influence of body condition score on relationships between metabolic status and oxidative stress in periparturient dairy cows. J. Dairy Sci. 88:2017-2026. http://dx.doi.org/10.3168/jds.S00220302(05)72878-2. 
Bertoni, G., E. Trevisi, X. Han, and M. Bionaz. 2008. Effects of inflammatory conditions on liver activity in puerperium period and consequences for performance in dairy cows. J. Dairy Sci. 91:33003310. http://dx.doi.org/10.3168/jds.2008-0995.

Bicalho, R. C., and G. Oikonomou. 2013. Control and prevention of lameness associated with claw lesions in dairy cows. Livest. Sci. 156:96-105. http://dx.doi.org/10.1016/j.livsci.2013.06.007.

Burgi, K., and N. Cook. 2006. A visual guide to scoring lesions of the claw using a modified ABC lesion scoring system. Page 179 in Proc. 14th International Symposium on Lameness in Ruminants, Colonia, Uruguay. Uruguayan Society of Veterinary Medicine, Montevideo, Uruguay.

Castillo, C., J. Hernandez, A. Bravo, M. Lopez-Alonso, V. Pereira, and J. L. Benedito. 2005. Oxidative status during late pregnancy and early lactation in dairy cows. Vet. J. 169:286-292. http://dx.doi. org/10.1016/j.tvjl.2004.02.001.

Castillo, C., J. Hernandez, I. Valverde, V. Pereira, J. Sotillo, M. L. Alonso, and J. L. Benedito. 2006. Plasma malonaldehyde (MDA) and total antioxidant status (TAS) during lactation in dairy cows. Res. Vet. Sci. 80:133-139. http://dx.doi.org/10.1016/j. rvsc.2005.06.003.

Ceciliani, F., J. J. Ceron, P. D. Eckersall, and H. Sauerwein. 2012. Acute phase proteins in ruminants. J. Proteomics 75:4207-4231. http://dx.doi.org/10.1016/j.jprot.2012.04.004.

Celi, P. 2011. Biomarkers of oxidative stress in ruminant medicine. Immunopharmacol. Immunotoxicol. 33:233-240. http://dx.doi.org /10.3109/08923973.2010.514917.

Cha, E., J. A. Hertl, D. Bar, and Y. T. Grohn. 2010. The cost of different types of lameness in dairy cows calculated by dynamic programming. Prev. Vet. Med. 97:1-8. http://dx.doi.org/10.1016/j. prevetmed.2010.07.011

Edmonson, A. J., I. J. Lean, L. D. Weaver, T. Farver, and G. Webster. 1989. A body condition scoring chart for holstein dairy cows J. Dairy Sci. 72:68-78. http://dx.doi.org/10.3168/jds.S00220302(89)79081-0.

Ghiselli, A., M. Serafini, F. Natella, and C. Scaccini. 2000. Total antioxidant capacity as a tool to assess redox status: Critical view and experimental data. Free Radic. Biol. Med. 29:1106-1114.

Goff, J. P., and R. L. Horst. 1997. Physiological changes at parturition and their relationship to metabolic disorders. J. Dairy Sci. 80:1260-1268.

Halliwell, B., and S. Chirico. 1993. Lipid peroxidation: Its mechanism, measurement, and significance. Am. J. Clin. Nutr. 57:715S-724S.

Huzzey, J. M., S. Mann, D. V. Nydam, R. J. Grant, and T. R. Overton. 2015. Associations of peripartum markers of stress and inflammation with milk yield and reproductive performance in Holstein dairy cows. Prev. Vet. Med. 120:291-297. http://dx.doi. org/10.1016/j.prevetmed.2015.04.011.

Lim, P. Y., J. N. Huxley, J. A. Willshire, M. J. Green, A. R. Othman, and J. Kaler. 2015. Unravelling the temporal association between lameness and body condition score in dairy cattle using a multistate modelling approach. Prev. Vet. Med. 118:370-377. http:// dx.doi.org/10.1016/j.prevetmed.2014.12.015.

Lykkesfeldt, J., and O. Svendsen. 2007. Oxidants and antioxidants in disease: Oxidative stress in farm animals. Vet. J. 173:502-511. http://dx.doi.org/10.1016/j.tvjl.2006.06.005.

Mavangira, V., M. J. Mangual, J. C. Gandy, and L. M. Sordillo. 2016. $15-\mathrm{F}_{2 \mathrm{t}}$-Isoprostane concentrations and oxidant status in lactating dairy cattle with acute coliform mastitis. J. Vet. Intern. Med. 30:339-347. http://dx.doi.org/10.1111/jvim.13793.

McArt, J. A., D. V. Nydam, G. R. Oetzel, T. R. Overton, and P. A. Ospina. 2013. Elevated non-esterified fatty acids and betahydroxybutyrate and their association with transition dairy cow performance. Vet. J. 198:560-570. http://dx.doi.org/10.1016/j. tvj1.2013.08.011.
Nonnecke, B. J., K. Kimura, J. P. Goff, and M. E. Kehrli Jr. 2003. Effects of the mammary gland on functional capacities of blood mononuclear leukocyte populations from periparturient cows. J. Dairy Sci. 86:2359-2368. http://dx.doi.org/10.3168/jds.S00220302(03)73829-6.

O’Boyle, N., C. M. Corl, J. C. Gandy, and L. M. Sordillo. 2006. Relationship of body condition score and oxidant stress to tumor necrosis factor expression in dairy cattle. Vet. Immunol. Immunopathol. 113:297-304. http://dx.doi.org/10.1016/j.vetimm.2006.05.013.

Ospina, P. A., D. V. Nydam, T. Stokol, and T. R. Overton. 2010. Evaluation of nonesterified fatty acids and b-hydroxybutyrate in transition dairy cattle in the northeastern United States: Critical thresholds for prediction of clinical diseases. J. Dairy Sci. 93:546554 .

Prentice, D. E. 1973. Growth and wear rates of hoof horn in Ayrshire cattle. Res. Vet. Sci. 14:285-290.

Proudfoot, K. L., D. M. Weary, and M. A. von Keyserlingk. 2010. Behavior during transition differs for cows diagnosed with claw horn lesions in mid lactation. J. Dairy Sci. 93:3970-3978. http://dx.doi. org/10.3168/jds.2009-2767.

Re, R., N. Pellegrini, A. Proteggente, A. Pannala, M. Yang, and C. Rice-Evans. 1999. Antioxidant activity applying an improved ABTS radical cation decolorization assay. Free Radic. Biol. Med. 26:1231-1237. http://dx.doi.org/10.1016/S0891-5849(98)00315-3.

Refaai, W., R. Ducatelle, P. Geldhof, B. Mihi, M. El-shair, and G. Opsomer. 2013. Digital dermatitis in cattle is associated with an excessive innate immune response triggered by the keratinocytes. BMC Vet. Res. 9:193. http://dx.doi.org/10.1186/1746-6148-9-193.

Shi, X., D. Li, Q. Deng, Y. Li, G. Sun, X. Yuan, Y. Song, Z. Wang, X. Li, X. Li, and G. Liu. 2015. NEFAs activate the oxidative stressmediated NF-kappaB signaling pathway to induce inflammatory response in calf hepatocytes. J. Steroid Biochem. Mol. Biol. 145:103-112. http://dx.doi.org/10.1016/j.jsbmb.2014.10.014.

Sordillo, L. M., and S. L. Aitken. 2009. Impact of oxidative stress on the health and immune function of dairy cattle. Vet. Immunol. Immunopathol. 128:104-109. http://dx.doi.org/10.1016/j. vetimm.2008.10.305.

Sordillo, L. M., and V. Mavangira. 2014. The nexus between nutrient metabolism, oxidative stress and inflammation in transition cows. Anim. Prod. Sci. 54:1204-1214. http://dx.doi.org/10.1071/ AN14503.

Sordillo, L. M., and W. Raphael. 2013. Significance of metabolic stress, lipid mobilization, and inflammation on transition cow disorders. Vet. Clin. North Am. Food Anim. Pract. 29:267-278. http://dx.doi.org/10.1016/j.cvfa.2013.03.002.

Sprecher, D. J., D. E. Hostetler, and J. B. Kaneene. 1997. A lameness scoring system that uses posture and gait to predict dairy cattle reproductive performance. Theriogenology 47:1179-1187. http:// dx.doi.org/10.1016/S0093-691x(97)00098-8.

Talukder, S., G. Gabai, and P. Celi. 2015. The use of digital infrared thermography and measurement of oxidative stress biomarkers as tools to diagnose foot lesions in sheep. Small Rumin. Res. 127:8085. http://dx.doi.org/10.1016/j.smallrumres.2015.04.006.

Wullepit, N., K. Raes, B. Beerda, R. F. Veerkamp, D. Fremaut, and S. De Smet. 2009. Influence of management and genetic merit for milk yield on the oxidative status of plasma in heifers. Livest. Sci. 123:276-282. http://dx.doi.org/10.1016/j.livsci.2008.11.013.

Zhang, G., D. Hailemariam, E. Dervishi, Q. Deng, S. Goldansaz, S. Dunn, and B. Ametaj. 2015. Alterations of innate immunity reactants in transition dairy cows before clinical signs of lameness. Animals 5:717-747. http://dx.doi.org/10.3390/ani5030381.

Zhao, X. J., X. Y. Wang, J. H. Wang, Z. Y. Wang, L. Wang, and Z. H. Wang. 2015. Oxidative stress and imbalance of mineral metabolism contribute to lameness in dairy cows. Biol. Trace Elem. Res. 164:43-49. http://dx.doi.org/10.1007/s12011-014-0207-1. 